\title{
Structure of aqueous electrolyte solutions near a hydrophobic surface
}

\author{
M.Kinoshita \\ Institute of Advanced Energy, Kyoto University, Uji, Kyoto 611-0011, Japan
}

Received May 5, 2007

\begin{abstract}
The structure of aqueous solutions of $1: 1$ salts $(\mathrm{KCl}, \mathrm{NaCl}, \mathrm{KF}$, and $\mathrm{Csl})$ near a hydrophobic surface is analysed using the angle-dependent integral equation theory. Water molecules are taken to be hard spheres imbedded with multipolar moments including terms up to octupole order, and hard spherical ions are immersed in this model water. The many-body interactions associated with molecular polarizability are treated at the self-consistent mean field level. The effects of cationic and anionic sizes and salt concentration in the bulk are discussed in detail. As the salt concentration increases, the layer of water molecules next to the surface becomes denser but its orientational order remains almost unchanged. The concentration of each ion at the surface can be drastically different from that in the bulk. As a striking example, at sufficiently low salt concentrations, the concentration of $\mathrm{I}^{-}$is about 500 times higher than that of $\mathrm{F}^{-}$at the surface.
\end{abstract}

Key words: water, electrolyte solution, hydrophobic surface, multipolar moment, integral equation theory

PACS: $61.20 . \mathrm{Gy}, 61.20 . \mathrm{Qg}, 61.25 . \mathrm{Em}$

\section{Introduction}

The aqueous electrolyte solution is an essential constituent of a system in a variety of fields such as solution chemistry, electrochemistry, biophysics, biochemistry, and colloidal science. Above all, the elucidation of the structure and properties of the solution at surfaces has been a central issue for decades. The solution at an extended, structureless hydrophobic surface is the most fundamental example to be investigated in the first stage, and the product of the investigation should provide basic information and important physical insights. Nevertheless, even for this simple system our microscopic understanding is not complete.

At present, computer simulations including water molecules and ions at finite concentration are problematic. Such simulations are usually performed by confining a fixed number of ions and water molecules between two plates, and there is no reliable way of estimating the bulk equilibrium concentration of ions. Grand Canonical Monte Carlo calculations could solve this problem but such calculations would be impractical [1]. This difficulty in computer simulations may be a major reason for the slow progress of our studies on aqueous electrolyte solutions at surfaces.

The integral equation theory does not suffer from the drawbacks found in computer simulations mentioned above. However, it is not straightforward to implement the analyses because of the presence of water molecules. The water-water and water-ion correlations are dependent not only on the distance between centers of the particles but also on the particle orientations. Treating the orientational correlations in an explicit manner is crucially important in analyses on the dielectric properties of aqueous electrolyte solutions [2]. Incorporating the effects of molecular polarizability is a nontrivial task. The water-surface correlations are also dependent on the orientations of water molecules. Further, the severe numerical instability is often encountered in solving the basic equations once the ionic concentration becomes finite.

Cares must be taken in choosing a water model when ions are included in water. In the multipolar model for water [2,3], the multipolar moments of a water molecule experimentally determined [4] are used. When ions are included, the water-ion electrostatic interaction potentials are accurately expressed by the dipole-ion, quadrupole-ion, and octupole-ion interactions. The SPC/E model [5], 
which is the most popular water model, is nearly optimized in computer simulations so that only the structure and properties of pure water can be reproduced. It is not definite if the water-ion electrostatic interaction potentials can be accurately described with the SPC/E model due to the potential impertinence of its multipolar moments.

In these 20 years, a great progress has been made in constructing the angle-dependent integral equation theories combined with the multipolar water model for aqueous electrolyte solutions in the bulk and at surfaces and in developing the robust numerical solution algorithms [2,3,6-22]. The inclusion of the octupole moment is essential because anions are more strongly hydrated than cations even when they share the same size and this effect can well be reproduced only by including the octupole moment. It is much easier to include ions in water at infinite dilution, and there are only several works $[8,9,13,17,20]$ dealing with aqueous electrolyte solutions where the ionic concentration is finite. In most of these works only the dipole moment and the quadrupole moment with tetrahedral symmetry are considered. The only exception is found in our earlier work [20] on the solutions near a simplified metal surface. In this article, we are concerned with the structure of the solutions near a hydrophobic surface for which the water-surface and ion-surface interactions are much weaker and the hydration properties of the ions are crucially important.

Here we consider aqueous solutions of $1: 1$ salts $(\mathrm{KCl}, \mathrm{NaCl}, \mathrm{KF}$, and $\mathrm{CsI}$ ): electrolyte solutions with ions of varying size, $\mathrm{K}^{+}, \mathrm{Na}^{+}, \mathrm{Cs}^{+}, \mathrm{F}^{-}, \mathrm{Cl}^{-}$, and $\mathrm{I}^{-}$. Water molecules are taken to be hard spheres imbedded with multipolar moments including terms up to octupole order [3], and hard spherical ions are immersed in this model water. The model solutions near a hydrophobic surface are studied by analysing the density profiles of cations, anions, and water molecules and the water orientational structure. The angle-dependent reference hypernetted-chain integral equation theory $[2,3,6-22]$ is employed. The many-body interactions associated with molecular polarizability are treated at the self-consistent mean field level [2,3]. The numerical solution of the basic equations is performed using our robust, highly efficient algorithms $[10,11,14-18,20-22]$. The major concern is to examine the effects due to cationic and anionic sizes and salt concentration in the bulk. We are interested in quantitative aspects of the conclusions as well as in qualitative arguments.

\section{Model}

A water molecule is modeled as a hard sphere of diameter $d_{\mathrm{S}}=0.28 \mathrm{~nm}$ in which a point dipole, quadrupole, and octupole are embedded [3]. Hard spherical cations and anions with diameters $d_{+}$ and $d_{-}$, respectively, are immersed in water. The diameters of the ionic species $\left(\mathrm{Na}^{+}, \mathrm{K}^{+}, \mathrm{Cs}^{+}, \mathrm{F}^{-}\right.$, $\mathrm{Cl}^{-}$, and $\mathrm{I}^{-}$), which are determined from x-ray electron density measurements $[2,23]$, are collected in table 1 . Since water molecules have $C_{2 v}$ symmetry, the dipole, quadrupole, and octupole moments have, respectively, 1, 2, and 2 mutually independent components [2].

Table 1. Diameters of hard spherical ions $(i=+,-)$.

\begin{tabular}{|l|l|}
\hline Ion & $d_{i} / d_{\mathrm{S}}$ \\
\hline $\mathrm{Na}^{+}$ & 0.84 \\
\hline $\mathrm{K}^{+}$ & 1.08 \\
\hline $\mathrm{Cs}^{+}$ & 1.28 \\
\hline $\mathrm{F}^{-}$ & 0.84 \\
\hline $\mathrm{Cl}^{-}$ & 1.16 \\
\hline $\mathrm{I}^{-}$ & 1.44 \\
\hline
\end{tabular}

The influence of molecular polarizability of water is included by employing the self-consistent mean field (SCMF) theory $[2,3]$. At the SCMF level the many-body induced interactions are reduced to pairwise additive potentials involving an effective dipole moment. The effective dipole moment thus determined is about 1.43 times larger than the bare gas-phase dipole moment. The values of the multipole moments used in the calculations are given elsewhere [20]. The dielectric constant of pure 
water predicted by the reference hypernetted-chain (RHNC) integral equation theory combined with the present model is 85.6 which is larger than the experimental value only by $\sim 10 \%$.

A hard sphere macroparticle of diameter $d_{\mathrm{M}}=30 d_{\mathrm{S}}$ is immersed at infinite dilution in the model aqueous electrolyte solutions. It interacts with water molecules and ions through the hard-sphere potentials and acts as a hydrophobic macroparticle. It has been shown that the size of $30 d_{\mathrm{S}}$ is large enough to mimic an extended surface [21,22]. The reason for employing hard-sphere repulsions is that the distance between particles and the distance between the surface and a particle can clearly be defined. The surface corrugation is neglected in the present model. However, it has been shown that the corrugation has remarkably little effect on the water structure near the surface [24], and this is probably true for the structure of aqueous electrolyte solutions.

Hereafter, the subscripts "S", "+", "-", and "M" denote "solvent (water)", "cations", "anions", and "macroparticle", respectively. We consider $0.25 \mathrm{M} \mathrm{KCl}, \mathrm{NaCl}, \mathrm{KF}$, and CsI solutions. For $\mathrm{KCl}$ solutions two more concentrations, 0.00M (at the infinite dilution limit) and $3.00 \mathrm{M}$, are also tested. The number densities of water molecules, cations, and anions in each solution are determined from the experimental solution density at $298 \mathrm{~K}$ and 1 atm $[25,26]$.

\section{Theory}

The Ornstein-Zernike (OZ) equation for the mixture comprising water molecules, cations, anions, and macroparticles can be written as [17]

$$
\begin{aligned}
& \eta_{\alpha \beta}(12)=\left\{1 /\left(8 \pi^{2}\right)\right\} \sum_{\gamma} \rho_{\gamma} \int c_{\alpha \gamma}(13)\left\{\eta_{\gamma \beta}(32)+c_{\gamma \beta}(32)\right\} \mathrm{d}(3), \\
& \eta_{\alpha \beta}(12)=h_{\alpha \beta}(12)-c_{\alpha \beta}(12), \quad \alpha, \beta=\mathrm{S},+,-, \mathrm{M}
\end{aligned}
$$

where $h$ and $c$ are the total and direct correlation functions, respectively, $(i j)$ represents $\left(\mathbf{r}_{i j}, \boldsymbol{\Omega}_{i}\right.$, $\left.\boldsymbol{\Omega}_{j}\right), \mathbf{r}_{i j}$ is the vector connecting the centers of particles $i$ and $j, \boldsymbol{\Omega}_{i}$ denotes the three Euler angles describing the orientation of particle $i, \int \mathrm{d}(3)$ represents integration over all position and angular coordinates of particle 3 , and $\rho$ is the number density. The closure equation is expressed by [17]

$$
\begin{aligned}
c_{\alpha \beta}(12) & =\int_{r}^{\infty}\left[h_{\alpha \beta}(12) \partial\left\{w_{\alpha \beta}(12)-b_{\alpha \beta}(12)\right\} / \partial r\right] \mathrm{d} r-u_{\alpha \beta}(12) /\left(k_{\mathrm{B}} T\right)+b_{\alpha \beta}(12), \\
w_{\alpha \beta}(12) & =-\eta_{\alpha \beta}(12)+u_{\alpha \beta}(12) /\left(k_{\mathrm{B}} T\right)
\end{aligned}
$$

where $u$ is the pair potential, $b$ is the bridge function, $r$ is the distance between the centers of two particles, $k_{\mathrm{B}}$ is the Boltzmann constant, and $T$ is the absolute temperature.

Since the macroparticles are present at infinite dilution $\left(\rho_{\mathrm{M}}=0\right)$, the calculation process can be split into two steps [17]:

(i) Solve equations (1) and (2) for the aqueous electrolyte solution comprising water molecules, cations, and anions. Calculate the correlation functions, $X_{\mathrm{SS}}, X_{\mathrm{S}+}, X_{\mathrm{S}-}, X_{++}, X_{+-}$, and $X_{--}(X=h, c)$.

(ii) Solve equations (1) and (2) for the aqueous electrolyte solution near a macroparticle using the correlation functions obtained in step (i) as input data. Calculate the correlation functions, $X_{\mathrm{MS}}, X_{\mathrm{M}+}$, and $X_{\mathrm{M}-}$.

For the numerical solution of equations (1) and (2), the pair potentials and correlation functions are expanded in a basis set of rotational invariants, and the basic equations are reformulated in terms of the projections $X_{\mu \nu}^{m n l}(r)$ occurring in the rotational-invariant expansion of $X[2,3,6-22]$. The expansion considered for $n_{\max } \leqslant 4$ gives sufficiently accurate results for uncharged surfaces. More details are described in earlier papers. The quantities we mainly analyse are the reduced density profiles $g_{\mathrm{MS} 00}^{000}, g_{\mathrm{M}+00}^{000}$, and $g_{\mathrm{M}-00}^{000}(g=h-1)$ which are denoted simply by $g_{\mathrm{MS}}, g_{\mathrm{M}+}$, and $g_{\mathrm{M}-}$, respectively. We also analyse the water orientational order at contact with the surface using 
the probability density functions $p(\theta)$ where $\theta$ is the angle with respect to the surface normal (into the aqueous solution) of either the molecular dipole $\left(\theta_{\mu}\right)$ or an $\mathrm{OH}$ bond $\left(\theta_{\mathrm{OH}}\right)$.

In the RHNC theory, the reference bridge functions are incorporated in the closure equations. The reference system in step (i) is a mixture of hard spheres of diameters $d_{\mathrm{S}}, d_{+}$, and $d_{-}$(the number densities are $\rho_{\mathrm{S}}, \rho_{+}$, and $\rho_{-}$, respectively), and that for step (ii) is a hard macrosphere of diameter $d_{\mathrm{M}}$ immersed in the hard-sphere mixture. In the present study, the particle-particle bridge functions needed in step (i) are estimated using the procedure developed by Lee and Levesque [27], and the macrosphere-particle bridge functions required in step (ii) are calculated in accordance with the method given by Henderson and Plischke [28].

A sufficiently long range $r_{L}$ is divided into $N$ grid points $\left(r_{m}=m \delta r, m=0,1, \ldots, N-1 ; \delta r=\right.$ $\left.r_{L} / N\right)$ and the projections for the pair potentials and correlation functions are represented by their values on these points. $N$ and $\delta r$ are set at 4096 and $0.01 d_{\mathrm{S}}$, respectively. The very large set of stiff, nonlinear simultaneous equations is solved using the robust, highly efficient algorithms developed by Kinoshita and coworkers [10,11,14-18,20-22].

\section{Results and discussion}

The calculations are performed for $0.25 \mathrm{M} \mathrm{KCl}, \mathrm{NaCl}, \mathrm{KF}$, and $\mathrm{CsI}$ solutions. For $\mathrm{KCl}$ solutions two more concentrations, $0.00 \mathrm{M}$ (at the infinite dilution limit) and $3.00 \mathrm{M}$, are also tested. The probability density functions $p\left(\theta_{\mathrm{OH}}\right)$ and $p\left(\theta_{\mu}\right)$ next to the hydrophobic surface are plotted in figures 1 and 2, respectively. They are shown for $0.00 \mathrm{M}$ and $3.00 \mathrm{M} \mathrm{KCl}$ solutions. The reduced

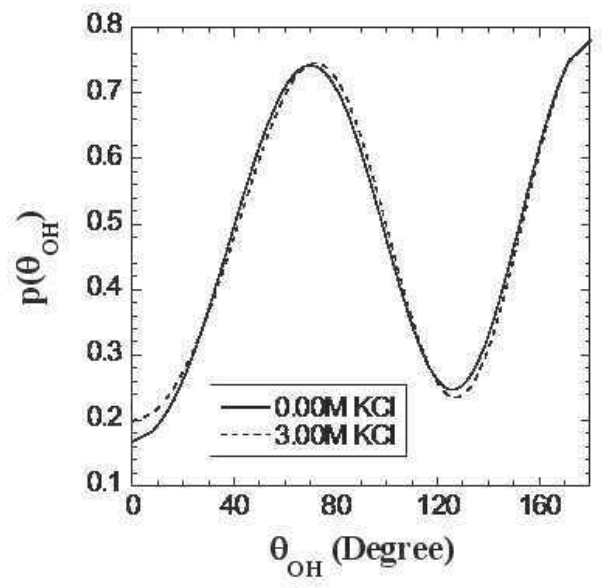

Figure 1. The probability density functions $p\left(\theta_{\mathrm{OH}}\right)$ next to the surface for $0.00 \mathrm{M}$ and $3.00 \mathrm{M} \mathrm{KCl}$ solutions.

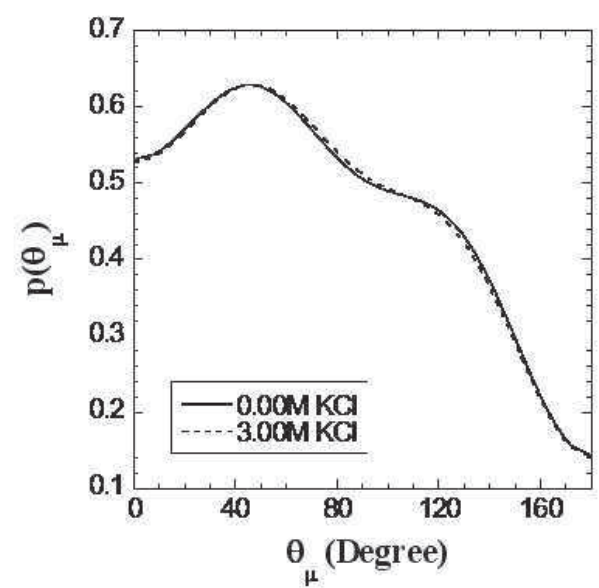

Figure 2. The probability density functions $p\left(\theta_{\mu}\right)$ next to the surface for $0.00 \mathrm{M}$ and $3.00 \mathrm{M}$ $\mathrm{KCl}$ solutions.

density profiles of water molecules near the surface are shown for $0.00 \mathrm{M}, 0.25 \mathrm{M}$, and $3.00 \mathrm{M} \mathrm{KCl}$ solutions in figure 3 and for $0.25 \mathrm{M} \mathrm{NaCl}$ and $\mathrm{CsI}$ solutions in figure $4\left(d_{\mathrm{M} 2}=d_{\mathrm{M}} / 2\right)$. The reduced density profiles of cations and anions for $0.25 \mathrm{M}$ solutions are shown in figures $5-8$. The oscillatory behavior of the curves in figures 3-8 is ascribed to the adoption of a molecular model for water. The values of the reduced density profiles of cations, anions, and water molecules at contact with the surface are summarized in table 2 for all the solutions tested. 
Table 2. Values of reduced density profiles of cations, anions, and water molecules at contact with the surface.

\begin{tabular}{|l|l|l|l|}
\hline Salt Solution & $g_{\mathrm{M}+, \text { Contact }}$ & $g_{\mathrm{M}-, \text { Contact }}$ & $g_{\mathrm{MS}, \text { Contact }}$ \\
\hline $0.00 \mathrm{M} \mathrm{KCl}$ & 0.1260 & 0.1863 & 1.5480 \\
\hline $0.25 \mathrm{M} \mathrm{KCl}$ & 0.2788 & 0.5237 & 1.6448 \\
\hline $3.00 \mathrm{M} \mathrm{KCl}$ & 0.6282 & 1.0926 & 2.3899 \\
\hline $0.25 \mathrm{M} \mathrm{NaCl}$ & 0.0226 & 0.5694 & 1.6585 \\
\hline $0.25 \mathrm{M} \mathrm{KF}$ & 0.2539 & 0.0090 & 1.6515 \\
\hline $0.25 \mathrm{M} \mathrm{CsI}$ & 1.6425 & 4.7153 & 1.6428 \\
\hline
\end{tabular}

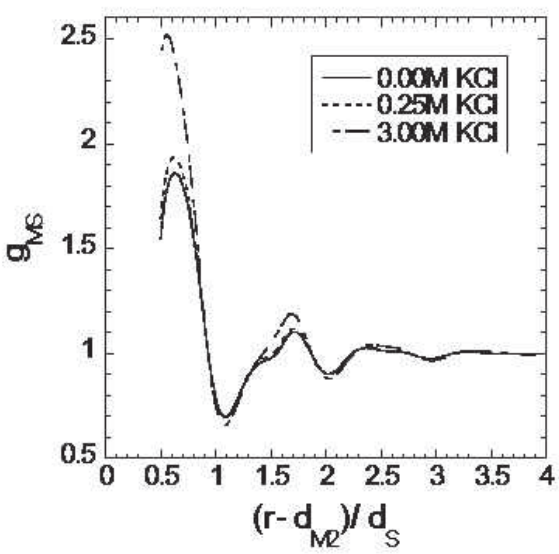

Figure 3. Reduced density profiles of water molecules for $0.00 \mathrm{M}, 0.25 \mathrm{M}$, and $3.00 \mathrm{M} \mathrm{KCl}$ solutions.

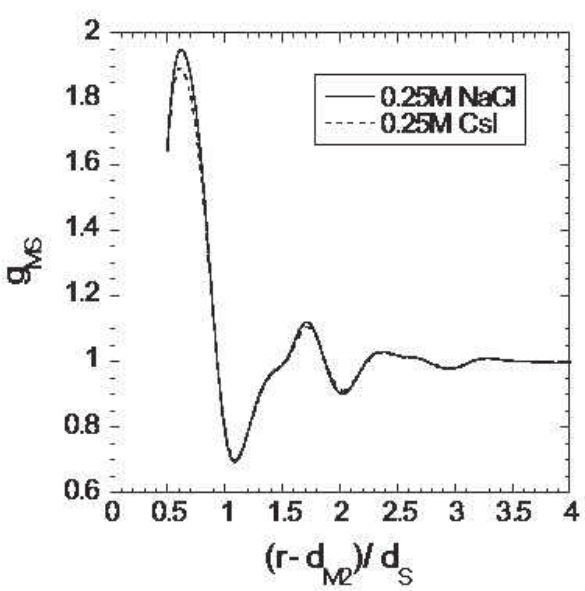

Figure 4. Reduced density profiles of water molecules for $0.25 \mathrm{M} \mathrm{NaCl}$ and CsI solutions.

\subsection{Orientational structure of water}

The probability density functions for pure water near the hydrophobic surface are identical to those for $0.00 \mathrm{M} \mathrm{KCl}$ solution shown in figures 1 and 2 . The function $p\left(\theta_{\mathrm{OH}}\right)$ in figure 1 indicates that at the contact with the surface is a dominant contribution from water molecules oriented with one $\mathrm{OH}$ bond directed into the surface: The local maxima occur at $\theta_{\mathrm{OH}} \sim 71^{\circ}$ and $180^{\circ}[21,22]$. This feature is also reflected in $p\left(\theta_{\mu}\right)$ plotted in figure 2 where it has a local maximum at $\theta_{\mu} \sim 55^{\circ}$ and a remnant of a local maximum at $\theta_{\mu} \sim 125^{\circ}[21,22]$. At the same time, $p\left(\theta_{\mu}\right)$ indicates a preference for dipoles inclined into the aqueous solution rather than toward the surface. This trend of $p\left(\theta_{\mu}\right)$ is considerably stronger than that reported by Torrie and Patey [12] who employed the Lee-Levesque (L-L) procedure [26] for the macrosphere-particle bridge functions as well. However, it should be noted that the L-L procedure gives pathological bridge functions when it is extended to such a large sphere immersed in small spheres [21]. The orientational order next to the surface persists until the salt concentration becomes as high as $3.00 \mathrm{M}$.

\subsection{Density profile of water molecules}

The reduced density profile of water molecules for pure water near the hydrophobic surface is identical to that for $0.00 \mathrm{M} \mathrm{KCl}$ solution shown in figure 3 . When a hydrophobic surface intrudes into water, it is impossible to maintain the hydrogen bonds as in the bulk and the loss of the bonds 


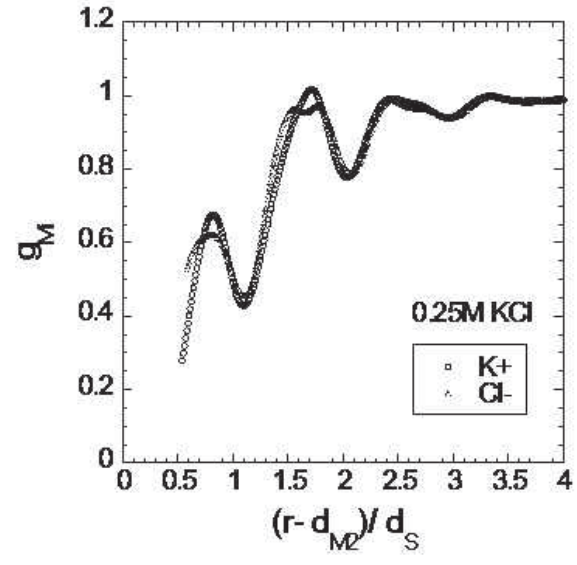

Figure 5. Reduced density profiles of ions for $0.25 \mathrm{M} \mathrm{KCl}$ solution $(i=+,-)$.

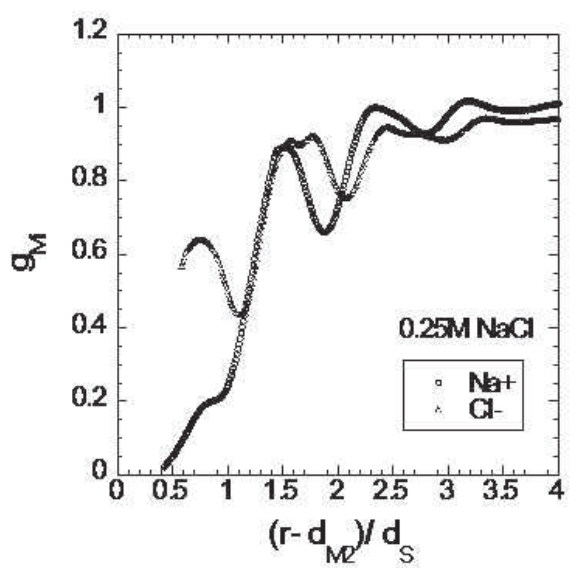

Figure 6. Reduced density profiles of ions for $0.25 \mathrm{M} \mathrm{NaCl}$ solution $(i=+,-)$.

is unavoidable. The loss is kept minimal by taking special orientations relative to the surface described above. In any case, the water molecules at contact are unfavorable, so the number of such molecules needs to be decreased. This dewetting effect competes with the entropic excludedvolume effect (or equivalently, the so-called packing force) causing the formation of a much denser layer near the surface as found in the hard-sphere solvent. Despite the dewetting effect, the contact value of the reduced density profile $g_{\mathrm{MS} \text {, Contact }}$ is higher than unity and the layer in the immediate vicinity of the surface is slightly denser than the bulk, which implies that the packing force still dominates.

The packing force becomes stronger as the total packing fraction $\eta_{\mathrm{T}}$ of the aqueous electrolyte solution increases for a salt species given. As the salt concentration increases, $\eta_{\mathrm{T}}$ becomes higher: The values of $\eta_{\mathrm{T}}$ for $0.00 \mathrm{M}, 0.25 \mathrm{M}$, and $3.00 \mathrm{M} \mathrm{KCl}$ solutions are, respectively, $0.3831,0.3854$, and 0.4066. As observed in figure 4 , with the increase in the salt concentration $g_{\mathrm{MS} \text {, Contact }}$ certainly increases and the layer in the immediate vicinity of the surface becomes denser.

For different species, the reduced density profile of water molecules is effected by the salt species as well as by $\eta_{\mathrm{T}}$. The values of $\eta_{\mathrm{T}}$ for $0.25 \mathrm{M} \mathrm{NaCl}$ and CsI solutions are, respectively, 0.3852 and 0.3864. However, $g_{\mathrm{MS} \text {, Contact }}$ is lower in the CsI solution. The reason for this is as follows. The ions are much larger in the CsI solution and they are preferentially excluded from the bulk to the surface (see figure 8) due to the weak hydration. This enrichment of ions leads to a less number of water molecules in the immediate vicinity of the surface.

\subsection{Effects of ionic sizes on density profiles of ions}

For $0.25 \mathrm{M}$ solutions, there is a depletion of $\mathrm{Na}^{+}, \mathrm{K}^{+}, \mathrm{F}^{-}$, and $\mathrm{Cl}^{-}$near the hydrophobic surface (see figures 5-7) because they are preferentially hydrated in the bulk. This is true even for $\mathrm{K}^{+}$ and $\mathrm{Cl}^{-}$which are larger than water molecules. In general, smaller ions are more depleted at a hydrophobic surface. Though $\mathrm{Na}^{+}$and $\mathrm{F}^{-}$share the same size, the depletion is more conspicuous for $\mathrm{F}^{-}$( " $g_{\mathrm{M}+\text {, Contact }}$ for $\mathrm{Na}^{+} " /$ " $g_{\mathrm{M}-\text {, Contact }}$ for $\left.\mathrm{F}^{-"}=2.51\right)$, which can well be reproduced only by including the octupole moment of water molecules. By contrast, $\mathrm{Cs}^{+}$and $\mathrm{I}^{-}$are considerably enriched in the close vicinity of the surface (see figure 8) because they can only weakly be hydrated and excluded from the bulk to the surface. In particular, $g_{\mathrm{M}-\text {, Contact }}$ for $\mathrm{I}^{-}$well exceeds 4 .

The difference between the curve for cations and that for anions in $0.25 \mathrm{M} \mathrm{KCl}$ solution is somewhat smaller than in $0.25 \mathrm{M} \mathrm{NaCl}, \mathrm{KF}$, and $\mathrm{CsI}$ solutions. The size of $\mathrm{Cl}^{-}$is only slightly larger than that of $\mathrm{K}^{+}$and anions are more strongly hydrated, leading to almost the same strength of 


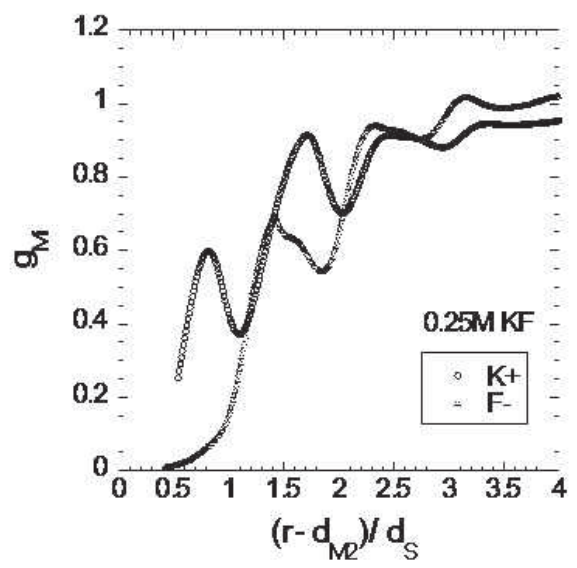

Figure 7. Reduced density profiles of ions for $0.25 \mathrm{M} \mathrm{KF}$ solution $(i=+,-)$.

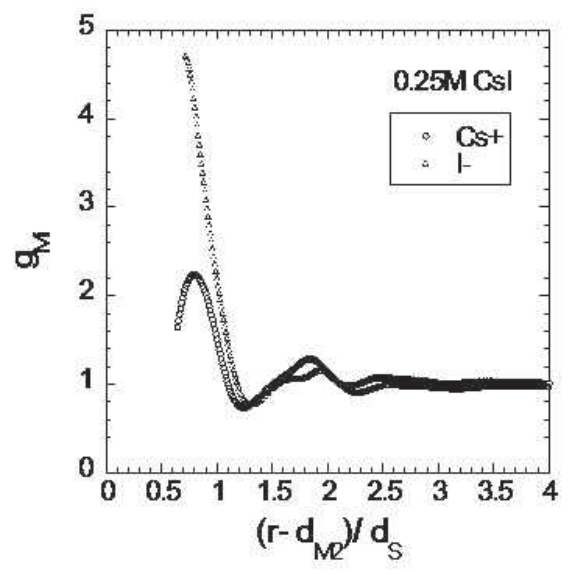

Figure 8. Reduced density profiles of ions for $0.25 \mathrm{M}$ CsI solution $(i=+,-)$.

the hydration followed by the small difference between the reduced density profiles of $\mathrm{Cl}^{-}$and $\mathrm{K}^{+}$.

\subsection{Effects of salt concentration on density profiles of ions}

The reduced density profiles of $\mathrm{K}^{+}$and $\mathrm{Cl}^{-}$are shown in figure 9 and figure 10, respectively. Those for $0.00 \mathrm{M}, 0.25 \mathrm{M}$, and $3.00 \mathrm{M} \mathrm{KCl}$ solutions are compared in these figures. The profiles shift upward at all separations as the salt concentration becomes higher. This is attributable mainly to the packing force which becomes larger as the salt concentration increases and $\eta_{\mathrm{T}}$ becomes higher.

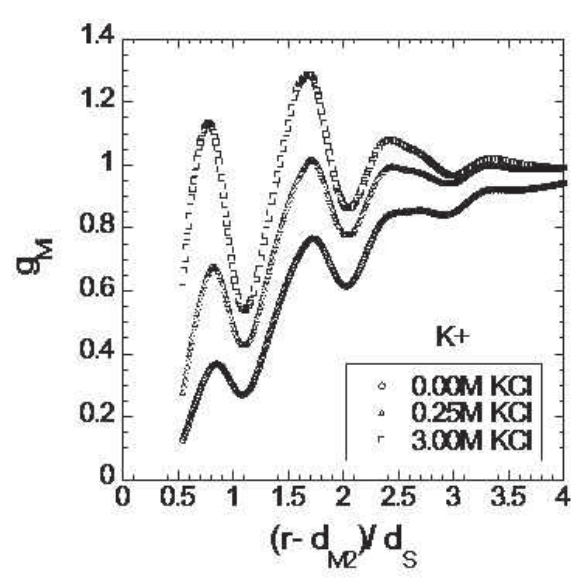

Figure 9. Reduced density profiles of $\mathrm{K}^{+}$ for $0.00 \mathrm{M}, 0.25 \mathrm{M}$, and $3.00 \mathrm{M} \mathrm{KCl}$ solutions $(i=+)$.

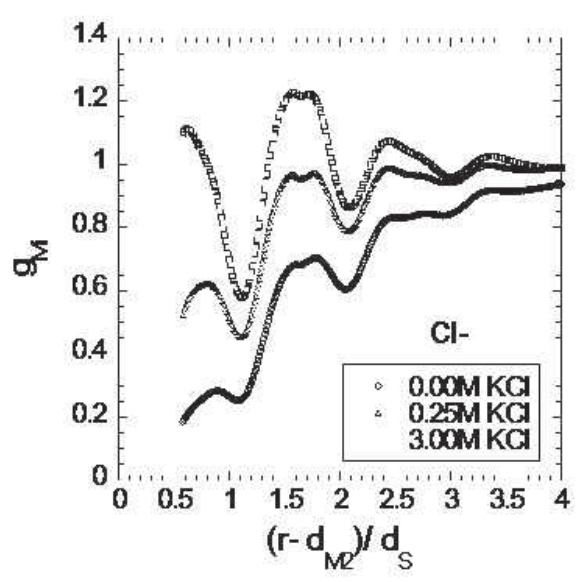

Figure 10. Reduced density profiles of $\mathrm{Cl}^{-}$ for $0.00 \mathrm{M}, 0.25 \mathrm{M}$, and $3.00 \mathrm{M} \mathrm{KCl}$ solutions $(i=-)$.

In $0.00 \mathrm{M}$ and $0.25 \mathrm{M}$ solutions, the ions $\left(\mathrm{K}^{+}\right.$and $\left.\mathrm{Cl}^{-}\right)$are depleted near the surface. In $3.00 \mathrm{M}$ 
solution, the reduced density profile for $\mathrm{K}^{+}$exceeds unity at some separations near the surface, but a slight depletion occurs. On the other hand, a slight enrichment is observed for $\mathrm{Cl}^{-}\left(g_{\mathrm{M}-\text {, Contact }}\right.$ is larger than unity) when the salt concentration reaches $3.00 \mathrm{M}$.

\subsection{Densities of ions at surfaces}

The reduced density profiles of $\mathrm{K}^{+}$for $0.25 \mathrm{M} \mathrm{KF}$ and $\mathrm{KCl}$ solutions are compared in figure 11. They are not significantly different from each other. Likewise, those of $\mathrm{Cl}^{-}$for $0.25 \mathrm{M}$ $\mathrm{NaCl}$ and $\mathrm{KCl}$ solutions are almost the same as shown in figure 12. Thus, at sufficiently low salt concentrations $(\leqslant 0.25 \mathrm{M})$, the reduced density profile of an ionic species is not significantly effected by the other ionic species which are co-present. Hence, the following examples can be given: $g_{\mathrm{M}+\text {, Contact }} / g_{\mathrm{M}-\text {, Contact }} \sim 180$ for $\mathrm{CsF}$ and $g_{\mathrm{M}-\text {, Contact }} / g_{\mathrm{M}+\text {, Contact }} \sim 210$ for NaI; and for the mixture of KF and KI, " $g_{\mathrm{M}-\text {, Contact }}$ for $\mathrm{I}^{-} " / " g_{\mathrm{M}-\text {, Contact }}$ for $\mathrm{F}^{-} " \sim 520$. Even when the concentrations of all ions are the same in the bulk, the concentration of an ionic species at the surface can be drastically different from that of another ionic species.

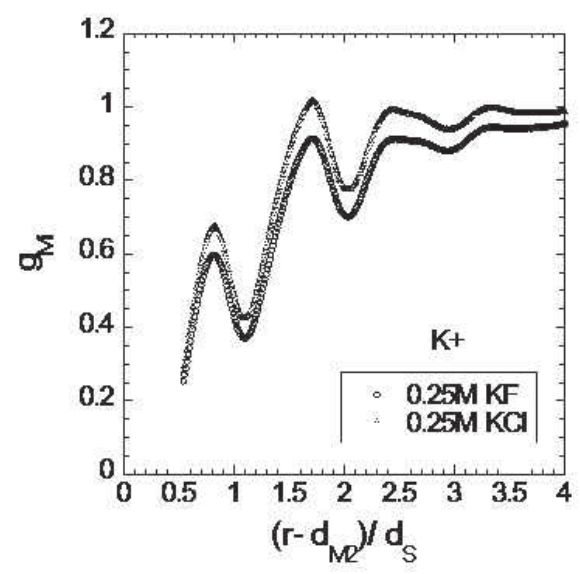

Figure 11. Reduced density profiles of $\mathrm{K}^{+}$for $0.25 \mathrm{M} \mathrm{KF}$ and $\mathrm{KCl}$ solutions $(i=+)$.

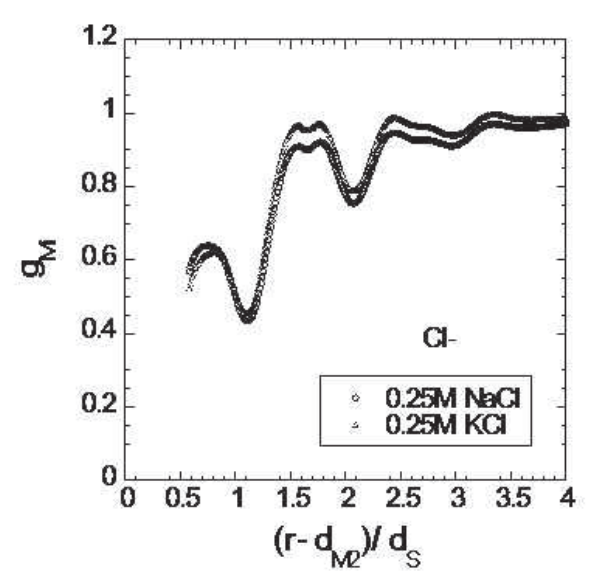

Figure 12. Reduced density profiles of $\mathrm{Cl}^{-}$for $0.25 \mathrm{M} \mathrm{NaCl}$ and $\mathrm{KCl}$ solutions $(i=-)$.

\section{Concluding remarks}

The structure of 1:1 electrolyte solutions near an extended hydrophobic surface is analysed using the angle-dependent RHNC theory combined with the multipolar model for water. The many-body interactions associated with molecular polarizability are treated at the SCMF level. Unlike the earlier works, the following two conditions are satisfied: (1) the ionic concentrations are finite; and (2) multipolar moments having terms up to octupole order are included.

The layer of water molecules next to the surface is slightly denser than the bulk and becomes progressively denser as the salt concentration increases. The orientational order of water molecules at contact with the surface is characterized by a tendency of one $\mathrm{OH}$ bond directed into the surface and a preference for dipoles inclined into the aqueous solution. This orientational order persists until the salt concentration becomes as high as 3.00M.

The ions, $\mathrm{Na}^{+}, \mathrm{K}^{+}$, and $\mathrm{F}^{-}$, are preferably hydrated in the bulk, and there is a depletion of these ions near the surface. The depletion is more conspicuous as the ionic size decreases and the hydration becomes stronger. Anions are more strongly hydrated than cations even when they share the same size: Though the sizes of $\mathrm{Na}^{+}$and $\mathrm{F}^{-}$are the same, the latter is more depleted. 
By contrast, $\mathrm{Cs}^{+}$and $\mathrm{I}^{-}$are considerably enriched near the surface because they are just weakly hydrated and excluded from the bulk to the surface. As for $\mathrm{Cl}^{-}$, they are depleted near the surface at low concentrations in the bulk but slightly enriched at high concentrations. Overall, the strength of the hydration in the bulk follows the order, $\mathrm{F}^{-}>\mathrm{Na}^{+} \gg \mathrm{K}^{+} \sim \mathrm{Cl}^{-} \gg \mathrm{Cs}^{+}>\mathrm{I}^{-}$.

Even when the concentrations of all ions are the same in the bulk, the concentration of an ionic species at the surface can be drastically different from that of another ionic species. For example, at sufficiently low salt concentrations $(\leqslant 0.25 \mathrm{M}), g_{\mathrm{M}+\text {, Contact }} / g_{\mathrm{M}-\text {, Contact }} \sim 180$ for $\mathrm{CsF}$ and $g_{\mathrm{M}-\text {, Contact }} / g_{\mathrm{M}+\text {, Contact }} \sim 210$ for NaI. For the mixture of KF and KI, " $g_{\mathrm{M}-\text {, Contact for }}$ $\mathrm{I}^{-"} /$ " $g_{\mathrm{M}-\text {, Contact }}$ for $\mathrm{F}^{-"} \sim 520$.

\section{Acknowledgements}

The author wishes to express his sincere thanks to Prof. G. N. Patey and Dr. D. R. Bérard for many fruitful discussions. This work was supported by Grants-in-Aid for Scientific Research on Priority Areas (No. 15076203) from the Ministry of Education, Culture, Sports, Science and Technology of Japan and by the Next Generation Super Computing Project, Nanoscience Program, MEXT, Japan.

\section{References}

1. Shelley J.C., Patey G.N., J. Chem. Phys., 1994, 100, 8265.

2. Kusalik P.G., Patey G.N., J. Chem. Phys., 1988, 88, 7715.

3. Kusalik P.G., Patey G.N., Mol. Phys., 1988, 65, 1105.

4. Verhoeven J., Dymanus A., J. Chem. Phys., 1970, 52, 3222.

5. Berendsen H.J.C., Grigera J.R., Straatsma T.P., J. Phys. Chem., 1987, 91, 6269.

6. Torrie G.M., Kusalik P.G., Patey G.N., J. Chem. Phys., 1988, 89, 3285.

7. Kusalik P.G., Patey G.N., J. Chem. Phys., 1988, 89, 5843.

8. Torrie G.M., Kusalik P.G., Patey G.N., J. Chem. Phys., 1989, 90, 4513.

9. Torrie G.M., Kusalik P.G., Patey G.N., J. Chem. Phys., 1989, 91, 6367.

10. Kinoshita M., Harada M., Mol. Phys., 1991, 74, 443.

11. Kinoshita M., Harada M., Mol. Phys., 1993, 79, 145.

12. Torrie G.M., Patey G.N., J. Phys. Chem., 1993, 97, 12909.

13. Wei D., Torrie G.M., Patey G.N., J. Chem. Phys., 1993, 99, 3990.

14. Kinoshita M., Harada M., Mol. Phys., 1994, 81, 1473.

15. Bérard D.R., Kinoshita M., Ye X., Patey G. N., J. Chem. Phys., 1994, 101, 6271.

16. Bérard D.R., Kinoshita M., Ye X., Patey G.N., J. Chem. Phys., 1995, 102, 1024.

17. Kinoshita M., Iba S., Harada M., J. Chem. Phys., 1996, 105, 2487.

18. Kinoshita M., Bérard D.R., J. Comput. Phys., 1996, 124, 230.

19. Cann N.M., Patey G.N., J. Chem. Phys., 1997, 106, 8165.

20. Bérard D.R., Kinoshita M., Cann N.M., Patey G.N., J. Chem. Phys., 1997, 107, 4719.

21. Kinoshita M., J. Sol. Chem., 2004, 33, 661.

22. Kinoshita M., J. Mol. Liq., 2005, 119, 47.

23. Morris D.F.C., Struct. Bonding, 1968, 4, 63.

24. Shelley J.C., Patey G.N., Bérard D.R., Torrie G.M., J. Chem. Phys., 1997, 107, 2122.

25. Washburn E.W., International Critical Tables, McGraw-Hill, New York, 1926.

26. Conway B.E., Verrall R.E., J. Phys. Chem., 1966, 70, 3952.

27. Lee L.L., Levesque D., Mol. Phys., 1973, 26, 1351.

28. Henderson D., Plischke M., Proc. R. Soc. London Ser. A, 1985, 400, 163. 


\title{
Структура водних розчинів електролітів поблизу гідрофобної поверхні
}

\author{
М.Кіношіта \\ Інститут новітньої енергетики, Університет м. Кіото, Кіото 611-0011, Японія \\ Отримано 5 травня 2007 р.
}

Структура водних розчинів $1: 1$ солей $(\mathrm{KCl}, \mathrm{NaCl}, \mathrm{KF}$, i Csl) поблизу гідрофобної поверхні аналізується в рамках теорії і орієнтовно залежних інтегральних рівнянь. Молекули води розглядаються як тверді сфери з вставленими мультипольними моментами включно до октупольного момента. Тверді сферичні іони поміщені в цю модель води. Багаточастинкові взаємодії, обумовлені молекулярною поляризованістю, трактуються на рівні самоузгодженого середнього поля. Детально обговорюються ефекти катіонних та аніонних розмірів і концентрацій солі в об'ємі . Із зростанням концентрації солі шари молекул води біля поверхні стають густішими, але ї орієнтаційний порядок залишається майже незмінним. Концентрація кожного з іонів біля поверхні може бути суттєво іншою, ніж в об'ємі. Як вражаючий приклад, при достатньо низьких концентраціях солі, концентрація I- біля поверхні майже в 500 раз вища, ніж концентрація $\mathrm{F}^{-}$.

Ключові слова: розчин електроліту, гідрофобна поверхня, мультипольний момент, теорія інтегральних рівнянь

PACS: $61.20 . \mathrm{Gy}, 61.20 . \mathrm{Qg}, 61.25 . \mathrm{Em}$ 